\title{
COMPARISON OF PREGNANCY AND POSTPARTUM PERIODS IN TERMS OF DEPRESSION LEVEL
}

\author{
Ş. Karayağız $z^{1}$, M. Uysal ${ }^{2}$, Ö. Bektaş ${ }^{3}$ \\ Nuh Naci Yazgan University, Psychology Department, Kayseri, Turkey
}

\begin{abstract}
Introduction.-Pregnancy is the period in which women have many biological and psychosocial changes. It also includes risk factors for depression and anxiety. Pregnancy depression is a common mental disorder that affects both the mother and the child. Pregnancy depression is also important because of the potential for suicide attempt and increases postpartum depression risk.

Objectives.-In this study, it was aimed to compare the depression levels of women during pregnancy and the level of depression of women who had recently delivered.

Methods.-The study was carried out with 44 women who were 16 weeks and older pregnant and 255 puerperant who applied to the health center. As measuring tools; sociodemographic data form, StateTrait Anxiety Inventory, Edinburgh Postnatal Depression Scale and Beck Depression Inventory were used.

Results.-As a result of the analyzes, it was found that according to Beck Depression Inventory the depression level of the pregnant women (Mean $=0.67, \mathrm{~S}=.38$ ) was significantly higher than the depression level of the women who had given birth recently (Mean $=0.50, S=.46)(p<0.05$ ).

Conclusion.-There are many sources of anxiety that pregnant women may worry about, such as giving birth to a healthy child, health of the baby, physiological changes in the body, and hormonal disorders. In the postpartum period the level of depression decreases because the effect level of these anxiety sources decreases.
\end{abstract}

Keywords: anxiety, depression, health, postpartum, preganancy 